\title{
Levantamento das medidas de manutenção aplicado nas estradas rurais na bacia do Rio das Pedras, Guarapuava-PR com avaliação qualitativa do estado de conservação
}

\author{
Identification of maintenance measures used in rural roads in Pedras river basin, \\ Guarapuava-PR with qualitative evaluation of the state of conservation
}

\author{
Márcia Cristina Cunha \\ Universidade Estadual do Centro Oeste do Paraná-UNICENTRO \\ Professora do Departamento de Geografia \\ marcia1cunha@yahoo.com.br
}

Rodrigo Vaz dos Santos
Graduado em Geografia pela Universidade Estadual do Centro Oeste do Paraná
$\underline{\text { rvazsantos@ig.com.br }}$

Anderson Aurélio da Cruz

Graduado em Geografia pela Universidade Estadual do Centro Oeste do Paraná andinho_gpuava@hotmail.com

Artigo recebido para revisão em 11/04/2014 e aceito para publicação em 23/05/2014

\begin{abstract}
Resumo
É de suma importância o deslocamento de pessoas em áreas rurais, juntamente com o transporte de informação, serviços e mercadorias, em que muitas destas atividades são oriundas do campo. Portanto o estudo voltado para as estradas não pavimentadas torna-se necessário. Este trabalho teve por objetivo caracterizar trechos de estradas não pavimentadas da Bacia Hidrográfica do Rio das Pedras (BRP), Guarapuava com um levantamento sobre medidas de manutenção em estradas rurais identificando as medidas adotadas na bacia do Rio das Pedras. Na metodologia utilizada, foi verificado em campo quais são os danos causados pela falta de manutenção e quais são as principais medidas adotadas para amenizar os impactos nas estradas rurais. Verificou-se nos pontos avaliados, que há dispositivos de drenagem, mas muitos desses estão sem manutenção ou estão inadequados, ou seja, foram construídos de forma irregular e por isso não têm a eficácia desejada, não contribuindo para a desaceleração do escoamento superficial.
\end{abstract}

Palavras-chave: Terreno dissecado, dispositivos de drenagem, transporte de informações.

\begin{abstract}
People deslocation in the countryside is of great importance, along with the transportation of information, goods and services, since many of this activities are originary from the rural area. Thus, a reasearh focused on the unpaved roads becomes necessary. This study aimed to characterize stretches of unpaved roads Bacia Hidrográfica do Rio das Pedras (BHRP), Guarapuava, Paraná, with a survey of maintenance measurements of the rural roads in order to identify the unpaved roads in the watershed of Rio das Pedras. The methodology used, it was verified in the field research what are the damages caused by the lack of maintenance and which are the lead measurements adopted to minimize impacts on the rural roads. In those assessment locations it was verified that there are drainage devices, but many of them are lacking support or they are inappropriate, anyways they were built irregularly, therefore without the desired efficiency that does not contribute towards the slowing of the superficial flow.
\end{abstract}

Key-words: Dissected terrain, drainage devices, information transportation. 


\section{INTRODUÇÃO}

O efeito hidrológico das estradas depende de muitos fatores, incluindo a localização desta na vertente, o desenho das estruturas de drenagem que afetam a rota da água através da bacia hidrográfica e a proporção ocupada pelas estradas (GUCINSKI et al., 2001). A grande maioria das estradas das zonas rurais foi construída de forma inadequada, porque não tinha o mínimo da engenharia. Sempre buscava atender as necessidades locais de locomoção e o traçado do relevo, que em muitas vezes por ser um terreno muito acidentado propicia o desenvolvimento do processo erosivo mais acelerado, deformando a pista de rolamento (BAESSO; GONÇALVES, 2003).

As atividades econômicas de qualquer país necessitam de uma infraestrutura de malha viária de qualidade, com estradas que possam ser utilizadas com segurança, que recebem manutenção frequente, redes de drenagem adequadas e sinalizadas entre outras melhorias, com isso impulsionando o desenvolvimento social e econômico (MACHADO et al., 2006).

Os problemas nas estradas correspondem a qualquer alteração na superfície da estrada que influencie negativamente as condições de rolamento, sendo que o estado de conservação de uma estrada depende da geometria horizontal e vertical, das características dos materiais, das intempéries, do tráfego e das práticas de manutenção e reabilitação (ODA, et al., 2007).

A proteção da qualidade da água requer que os sedimentos gerados a partir de estradas não sejam transferidos aos rios. Portanto medidas adequadas de manunteção sao fundamentais para minimizar esses processos, (LANE et al., 2006).

De todo modo a pesar da importância que as estradas representam para a locomoção da população local, existe uma lacuna nas pesquisas em relação aos efeitos hidrogeomorfológicos em que pouco se sabe ainda sobre os seus efeitos nas áreas rurais.

Muitas vezes os recursos financeiros aplicados para práticas de conservação de estradas não são igualmente aplicados variando de uma região para outra por conta da utilidade que esta representa para a região. Portanto, as atividades de gerenciamento de estradas rurais são em sua maioria não planejadas e dependentes de táticas improvisadas como a implantação de dissipadores de energia (caixas de contenção, valas laterais, lombadas, técnicas de proteção vegetal, entre outras). O estudo adequado das estradas de terra ou "estradas vicinais" possibilita a correta manutenção das mesmas se isso for do interesse das autoridades locais, permitindo assim, a correta aplicação do dinheiro público.

A adequação das estradas rurais é imprescindível de modo que integre as práticas de manejo quanto ao uso do solo dentro da bacia hidrográfica resultando em um melhor controle da erosão, bem como a redução dos custos com a manutenção em torno de $70 \%$, representando uma economia 
ao município e também para os produtores rurais que garantirão o tráfego normal o ano inteiro (BUBLITZ; CAMPOS, 1992).

A manutenção dessas vias pode ser definida como a junção de elementos que visem à segurança no transporte, economia de capital tanto para moradores quanto aos cofres públicos e proporcionem certo conforto aos usuários que utilizam as estradas rurais.

Sendo assim o trabalho aqui apresentado teve por objetivo fazer uma avaliação qualitativa com um levantamento das medidas de manutenção que são aplicados na BRP para contribuição ao gerenciamento de vias visando melhorar o desempenho das estradas rurais e proteção da qualidade do solo e da água. Objetivou-se também por meio de entrevistas com os funcionários responsáveis pelo trabalho de manutenção obter respostas em relação do estado de conservação das estradas rurais.

\section{MATERIAIS E MÉTODOS}

\section{1 Área de estudo}

A BRP possui área de aproximadamente $330 \mathrm{~km}^{2}$, localiza-se no município de Guarapuava, no Estado do Paraná, entre as latitudes $25^{\circ} 13^{\prime} 10^{\prime \prime}$ S e $25^{\circ} 26^{\prime} 24^{\prime \prime}$ S e longitudes $51^{\circ} 13^{\prime} 10^{\prime \prime}$ W e $51^{\circ} 28^{\prime} 40^{\prime}$ 'W (Figura 1). O Rio das Pedras é um dos principais formadores do Rio Jordão, que por sua vez é um dos maiores afluentes da margem direita do Rio Iguaçu. O Rio das Pedras está instalado na unidade de rochas básicas da Formação Serra Geral. Na Bacia Sedimentar do Paraná essa unidade é a que possui maior extensão superficial, constituindo substrato de significativa porção da paisagem geomorfológica (LIMA, 2009).

O Rio das Pedras tem como principais afluentes os seguintes rios e arroios: margem esquerda: Rio Faxinal, Rio das Pombas, Rio Arroio Lajeadinho e Rio Guabiroba; margem direita: Rio das Mortes, Rio Arroio da Fraqueza, Rio do Cachorro, Rio Arroio Matão e Rio Campo de Dentro (LIMA, 1999).

É importante ressaltar também que as principais nascentes que formam o Rio das Pedras encontram-se na Área de Proteção Ambiental (APA) da Serra da Esperança, instituída pela Portaria Federal n. 507/02, de 17 de dezembro de 2002.

Em relação ao clima, Guarapuava, está sob o domínio da zona extratropical, o que resulta em temperaturas com caráter mesotérmico, temperaturas anuais médias entre $16^{\circ}$ e $20^{\circ} \mathrm{C}$, inverno frio e verão amenizado pelas altitudes (THOMAZ e VESTENA, 2003). A classificação climática do município, segundo Köppen, classifica-se como $\mathrm{Cfb}$, o que significa que o clima é pluvial, sempre úmido, com verões chuvosos e frescos (MAACK, 1981). É classificado como subtropical mesotérmico - úmido - sem estação seca, com verões frescos e invernos moderados. 


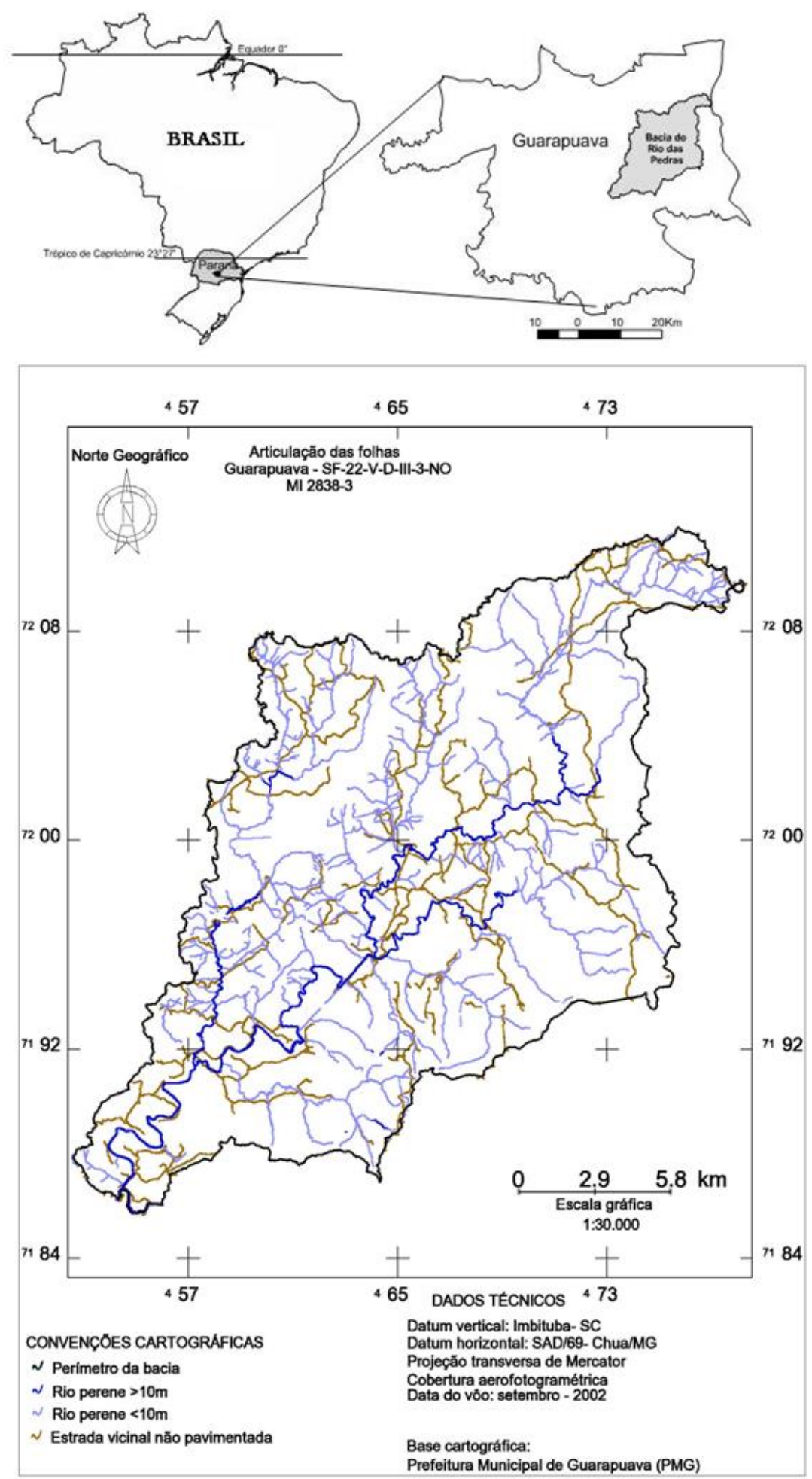

Figura 1 - Localização da bacia hidrográfica do Rio das Pedras Elaborado pelos autores (2014)

O uso da terra, de modo geral, na BRP é diversificado, envolvendo atividades relacionadas à agricultura, a pecuária, a indústria, ao florestamento/reflorestamento, mata, campo, capoeira, entre outras. A água para abastecimento público da cidade de Guarapuava é captada na bacia do Rio das Pedras. Diante disso, a forma correta do uso da terra na BRP é fundamental para prevenção e/ou mitigação dos problemas ambientais. 


\subsection{Compilação dos dados}

A revisão bibliográfica referiu-se à etapa da pesquisa onde se buscou a fundamentação teórica por meio da leitura e observações acerca dos sistemas hidrogeomorfológicos para associar e enriquecer a pesquisa. Já os trabalhos de gabinete consistiram na reunião das informações necessárias à execução da pesquisa (banco de dados da BRP), e a escolha das informações mais expressivas para a pesquisa.

Após a reunião das referências bibliográficas e material cartográfico, procedeu-se à manipulação dos dados nos trabalhos de laboratórios. Os mapas foram elaborados no Laboratório de Geoprocessamento (LABOGEO) do Departamento Geografia da UNICENTRO. Foi utilizado o software SPRING - INPE@ Versão 5.2.6 - Sistema de Processamento de Informações Georreferenciadas (Copyright - Instituto Nacional de Pesquisas Espaciais - INPE), desenvolvido pela Divisão de Processamento de Imagens - DPI do Instituto Nacional de Pesquisas Espaciais (INPE). O computador utilizado foi tipo notebook com processador Intel, 4 GB de memória, HD de $500 \mathrm{~GB}$, para o processamento dos dados no formato digital.

A base cartográfica utilizada foi a Carta Topográfica de Guarapuava editada pelo Ministério do Exército, Departamento de Engenharia e Comunicações. A articulação das folhas SG22-V-D-III3-NO/ MI 2838-3 e a Base Cartográfica da Prefeitura Municipal de Guarapuava (PMG); escala: 1:30.000, cedida em forma digital.

Os trabalhos de campo incidiram na obtenção de dados, interpretação e também na análise das informações obtidas. Na avaliação dessas estradas de terra, foram considerados os problemas, que são encontrados na plataforma, como buracos e ravinas, condições de drenagem e como estão implantados os mecanismos que servirão para reduzir o escoamento superficial, como por exemplo, as caixas de contenção.

Foram selecionados 2 trechos para avaliação qualitativa das estradas rurais, em que compreende alta e baixa vertente da bacia, Figura 2.

Nestes pontos foi observada a declividade da estrada, declividade do barranco, condições da plataforma da via, presença de vegetação, disponibilidade de material para ser transportado, entre outros critérios que se fizeram necessário. Para isso houve a utilização de alguns equipamentos, como: trena laser (DLE 50 Professional), trena métrica, suporte de madeira, clinômetro (CST), GPS de navegação, máquina fotográfica digital, prancheta e caderneta para anotação, foram de extrema importância.

As entrevistas foram realizadas com funcionários da prefeitura que fazem os trabalhos de manutenção das estradas rurais em questão. A forma de abordagem foi por meio de perguntas semiestruturada com questões abertas e fechadas que atende os objetivos da pesquisa. 


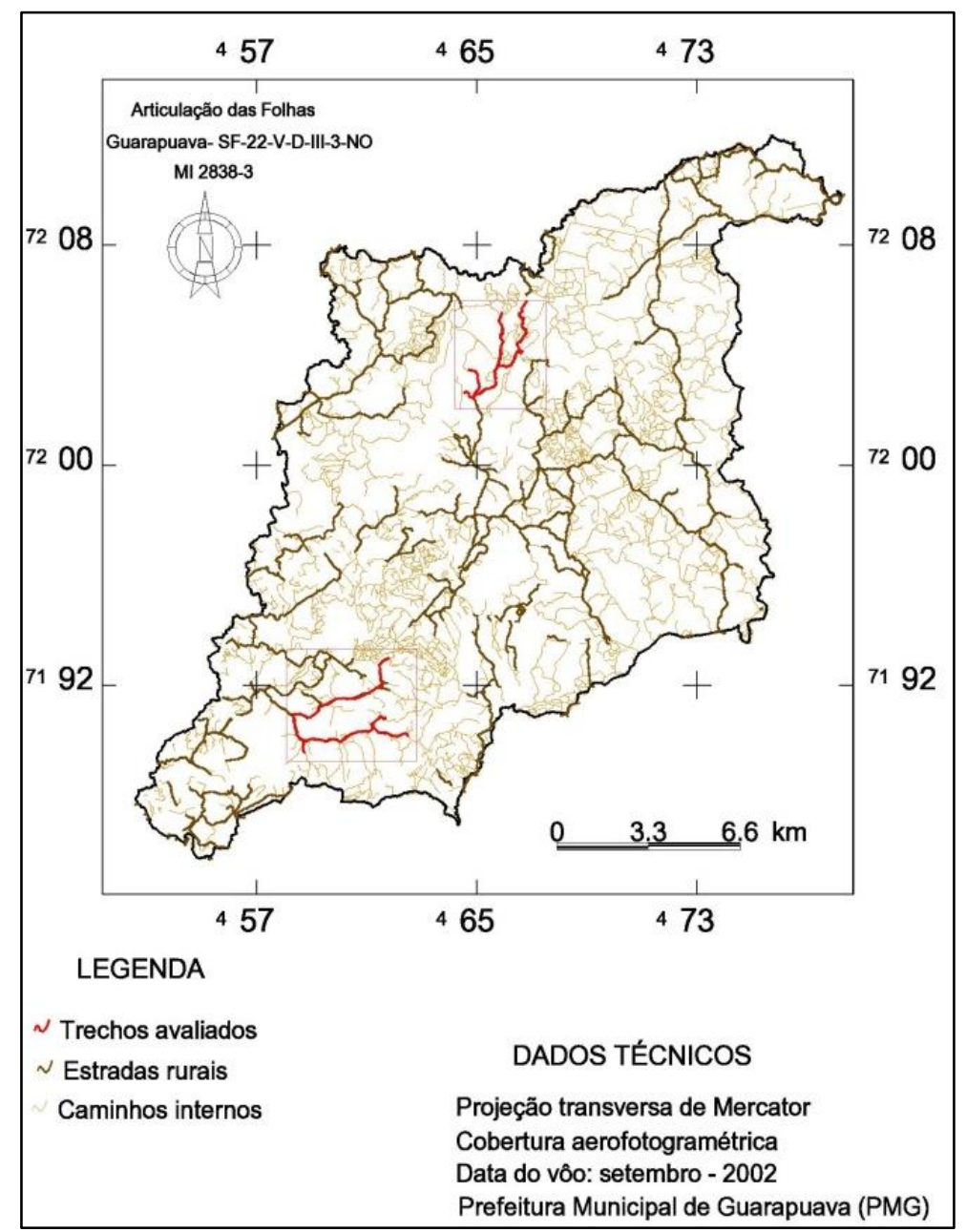

Figura 2 - Localização dos trechos avaliados da bacia hidrográfica do Rio das Pedras Elaborado pelos autores (2014)

\section{RESULTADOS E DISCUSSÃO}

\subsection{Características das estradas rurais da BRP}

As estradas vicinais da BRP foram construídas de forma a acompanhar os cursos dos rios considerando que é mais viável a sua construção, pois sendo implantadas em tais condições utiliza a melhor localização e facilidades do terreno, Figura 3.

Contudo a localização destas estradas e a sua proximidade com os cursos d'água podem aumentar o transporte de sedimentos, pois se deve realizar nesses trechos técnicas que contribuam com a minimização dos problemas gerados pelas mesmas por meio principalmente do assoreamento.

A camada superficial das estradas de terra em geral sofre constantemente com a erosão. Sobretudo a BRP, que está localizada num relevo significativamente acidentado, Figura 4, predominando o ondulado ( $8 \%$ a $20 \%$ ) em $44 \%$ da área total da bacia tais problemas ocorrem com maior intensidade, o que resulta na deformidade da pista de rolamento, surgindo ravinas, material solto para transporte e pista escorregadia. 


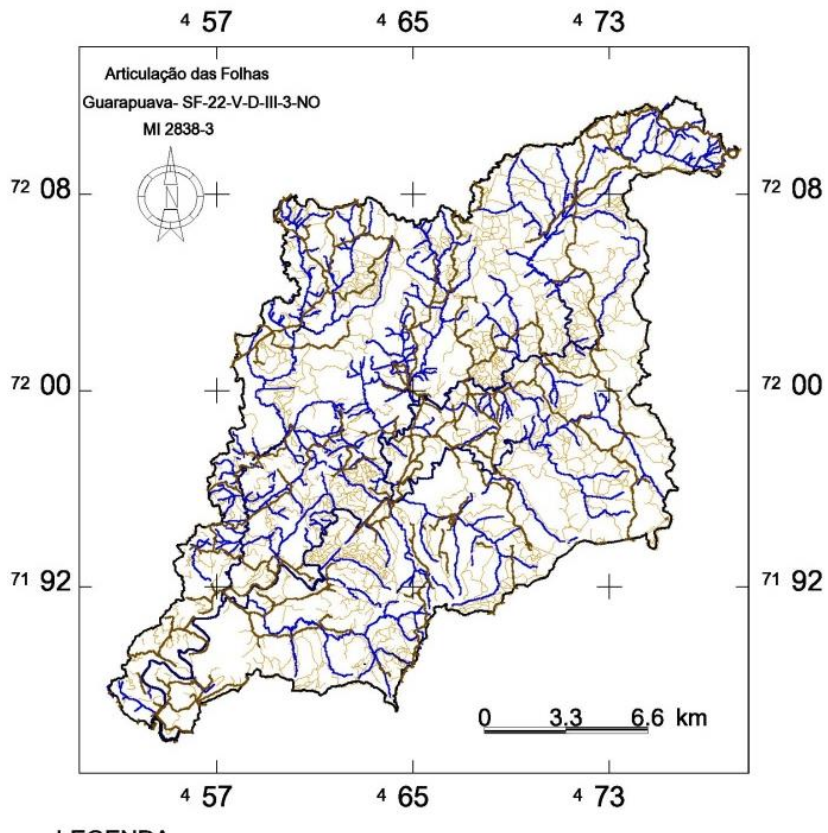

LEGENDA

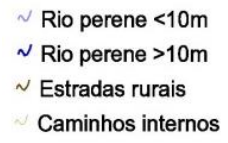

DADOS TÉCNICOS

Projeção transversa de Mercator

Cobertura aerofotogramétrica

Data do vôo: setembro - 2002

Prefeitura Municipal de Guarapuava (PMG)

Figura 3 - Rede viária e rede de drenagem da bacia hidrográfica do Rio das Pedras Elaborado pelos autores (2014)

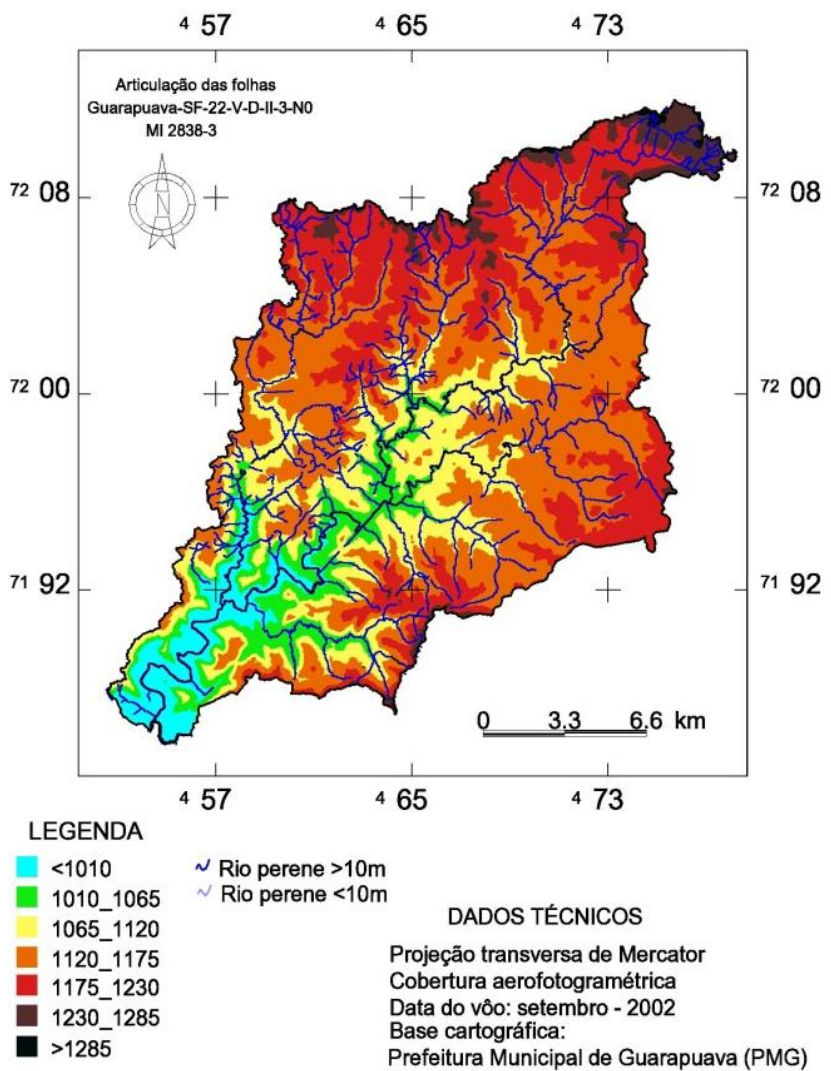

Figura 4 - Hipsometria da bacia hidrográfica do Rio das Pedras Elaborado pelos autores (2014) 
No caso dessas estradas, a maioria dos trechos avaliados possui cascalho ${ }^{1}$ agregado na plataforma, principalmente nas consideradas principais onde o tráfego é maior, já nas secundarias, boa parte apresenta-se sem cascalho.

Constatou-se que muitos dos problemas nas estradas da bacia em questão ocorrem quando o sistema de drenagem não está adequado, ou seja, os mecanismos adotados na via, sendo esses caixas de contenção, lombadas e técnicas de vegetação não desempenham a função que é dissipar energia, como observamos nos trechos avaliados a seguir.

\section{Trecho 1}

Localizado entre as coordenadas de Latitudes S $25^{\circ} 23^{\prime}$ '94' e S $25^{\circ} 23^{\prime} 26^{\prime \prime}$ e Longitudes W 51²3' 94', Z $1063 \mathrm{~m} \mathrm{e} \mathrm{Z} 1032 \mathrm{~m}, 4,5 \mathrm{~km}$ de extensão do trecho avaliado. O trecho avaliado tem a plataforma regular, revestimento com cascalho. Não há dissipadores de energia, do lado esquerdo o talude mede 1,70 m com presença de vegetação e cultivo de eucalipto, ao lado direito, o talude possui cerca de $0,15 \mathrm{~m}$ de altura, sendo que nesse mesmo lado existe uma cerca de arame farpado, e presença de agricultura. $\mathrm{O}$ trecho possui valas em ambos os lados, nestas podemos notar a presença de vegetação, sinal da falta de manutenção nos sistema de drenagem. A largura média da estrada é de 3,50 m. Não existem dissipadores de energia, e possui pouco material a ser transportado, Figura 5.

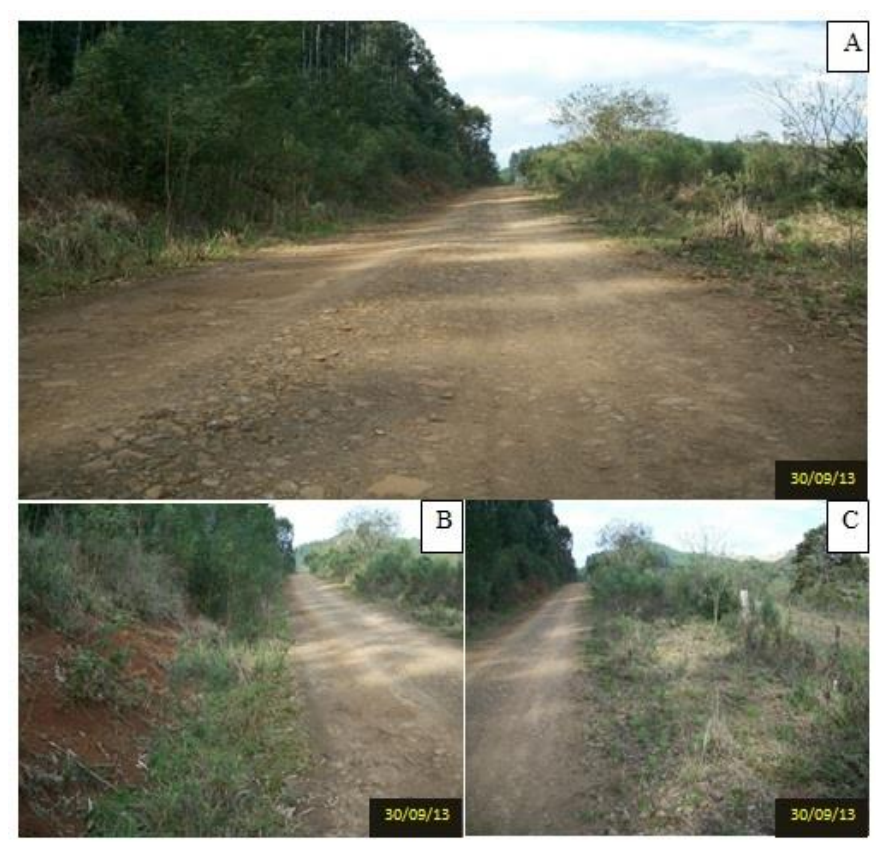

Figura 5 - Características das Estradas Rurais da Bacia do Rio das Pedras. Em A, estrada secundária sem manutenção periódica. Em B, presença de vegetação no talude e na vala lateral. Em C, presença de cerca de arame farpado e agricultura lado esquerdo da via.

Foto dos autores.

\footnotetext{
${ }^{1}$ Camada de cascalho serve para drenar a água como se fossem os lençóis de água sob a superfície do solo e também serve para dar mais conforto ao usuário da estrada diminuindo a formação de buracos.
} 
Neste ponto encontramos locais com plataforma em condições regulares, sem revestimento em alguns trechos, sem técnicas de proteção vegetal sendo que a maior parte do trecho possui em seus taludes cercas de arame farpado que separam as propriedades. Possui valas em alguns pontos, mas na maioria dos pontos buracos e poeira.

A plataforma encontra-se sem cascalho, com a presença de vegetação no centro, por conta da baixa trafegabilidade e falta de manutenção recorrente, pois o mesmo interliga fazendas para a estrada principal. Conforme Baesso e Gonçalves (2003) a deficiência do revestimento primário, quanto a sua mistura e aplicação na plataforma da estrada quando o trecho apresenta deficiência na drenagem superficial, ocasionará deformidades na pista e desconforto ao usuário.

O sistema de drenagem é bem mal conservado, possuindo apenas alguns dissipadores de energia por se tratar de estrada secundária a manutenção não é realizada ou realizada com dificuldade, Figura 6.

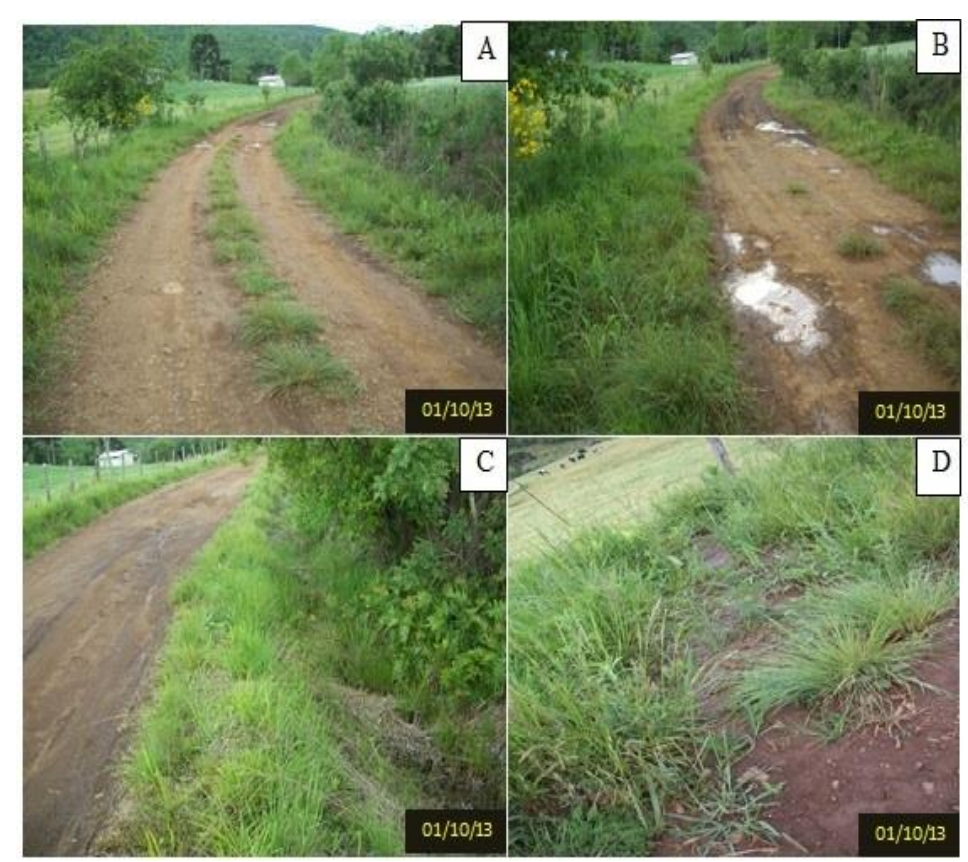

Figura 6 - Características das Estradas Rurais da Bacia do Rio das Pedras, Ponto. Em A, trecho de estrada secundária, vegetação ao centro. Em B, trecho com vários buracos ocasionado pelo tráfego de veículos e a falta de um sistema de drenagem adequado, retirando o revestimento primário. Em $\mathrm{C}$ vala a margem direita da via com presença de muita vegetação. Em D, presença de sedimentos finos escoados para um dissipador de energia (caixa de contenção).

Foto dos autores.

\section{Trecho 2}

Encontra-se entre as coordenadas de Latitudes S $25^{\circ} 22^{\prime} 71^{\prime \prime}$ e S $25^{\circ} 21^{\prime} 61^{\prime \prime}$, e Longitudes W 51²2"72", e W 51²'38", Z $1061 \mathrm{~m}$ e $1055 \mathrm{~m}$, tendo o trecho avaliado cerca de 3,5 km de extensão. A plataforma encontram-se danificada em diversos pontos e não possui revestimento na faixa de rolamento. A altura do talude é de 1,20 m margem esquerda, 0,35 m margem direita, sendo que nestes ocorre à presença de muita vegetação. A estrada tem uma largura média de 5,10 m. 
Existem caixas de contenção, porém sem manutenção, disponibilidade de muito material para ser transportado, pouca poeira e vários buracos, Figura 7.

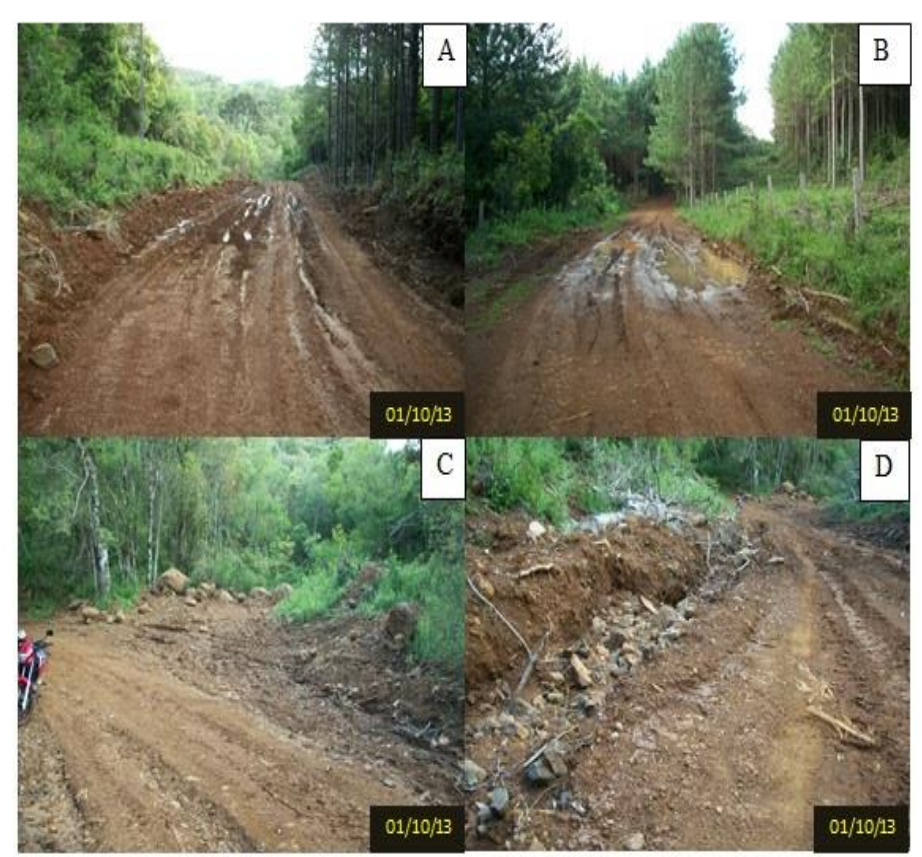

Figura 7 - Características das Estradas Rurais da Bacia do Rio das Pedras. Em A e B, plataforma onde a água se acumula (sistema de drenagem inapropriado e/ou ausente). Trecho sem estrutura adequada para escoamento. Em C, dissipado de energia com grande quantidade de material transportado. D, estrada em solo nu, com talude dissecado e erodido na lateral esquerda sem presença de revestimento.

Foto dos autores.

Encontramos neste trecho a estrada com plataforma irregular, com um revestimento de cascalho em apenas alguns locais da estrada dificultando a trafegabilidade principalmente em dias de chuva. No talude ao lado direito, possui cerca de 1,80 m, existe a presença de cerca de arame farpado com presença de proteção vegetal, sendo a maior parte de vegetação nativa.

Na margem esquerda mede $0,70 \mathrm{~m}$, sem construções, sendo que possui vegetação e a estrada fica bem próximo do Rio das Pedras, o que segundo Gonçalves (2002), Baesso e Gonçalves (2003) a correta localização das estradas na paisagem é o que as define como aceitáveis do ponto de vista ambiental, pois estradas adequadamente traçadas permitem que os impactos ambientais sejam menores. Como princípios básicos, o traçado deve ser localizado o mais próximo possível aos divisores de água, principalmente quando as estradas forem principais, e deve-se evitar a construção de estradas em áreas úmidas, instáveis, com fortes rampas e perto das áreas de preservação permanente.

Não há presença de sistema de drenagem. A largura média da estrada possui 4,80 m, possui tráfego intenso por se tratar de uma via principal que liga a BR 277. Presença de muitos buracos e pouca poeira, Figura 8. 


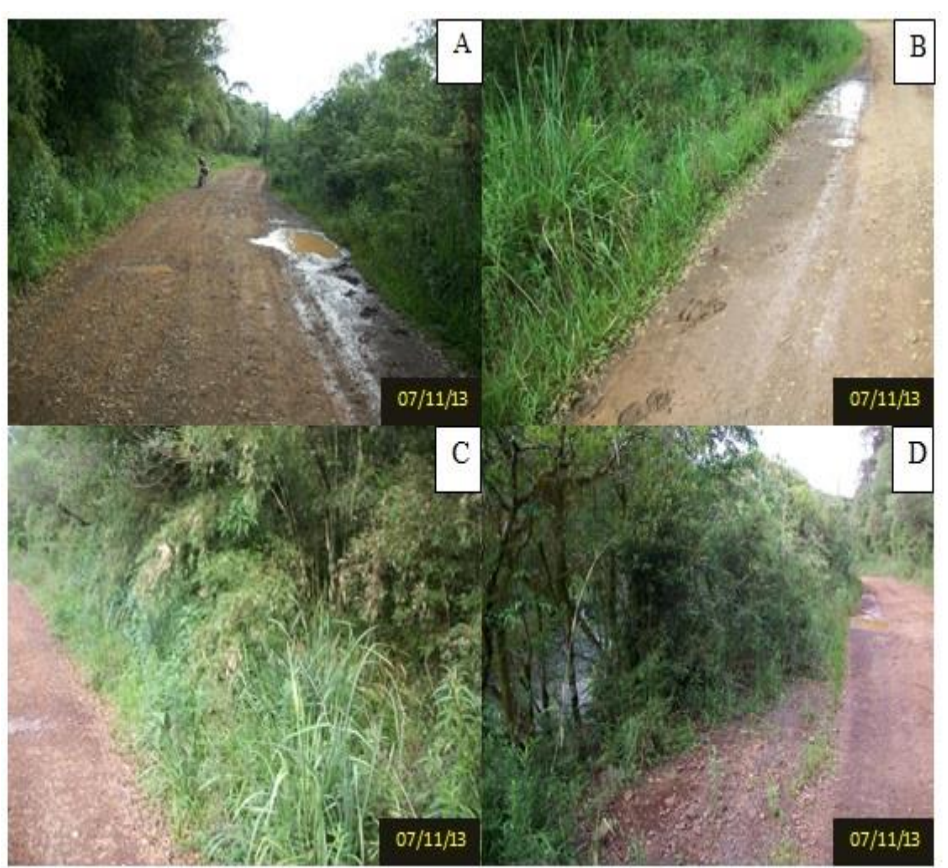

Figura 8 - Características das Estradas Rurais da Bacia do Rio das Pedras. Em A, trecho sem sistema de drenagem adequado, resultando no acumulo de água sobre a plataforma. Em B, presença de materiais finos a margem esquerda da via, transportados pela enxurrada. Em C, presença de muita vegetação no talude direito da estrada. Em D, presença de vegetação a margem esquerda ao lado do rio das Pedras.

Foto dos autores.

Portanto nota-se que existem vários problemas nas estradas rurais na BRP, e para que estes problemas sejam amenizados é de fundamental importância que sejam realizados trabalhos de manutenção periódica bem como acompanhamento do estado de conservação dessas vias, levando sempre em consideração a localização da mesma.

Baesso e Gonçalves (2003) destacam que as operações de manutenção podem ser divididas em manutenção corretiva rotineira e preventiva periódica, sendo que a primeira destas ocorre mais vezes ao ano e tem por finalidade manter todos os elementos da estrada, com o mínimo possível de alterações, com as mesmas características e condições que apresentavam logo após a sua construção. E a segunda, visa evitar o surgimento ou agravamento dos problemas, preservar as características superficiais, a integridade estrutural, e serventia da rodovia.

Para a prevenção e o controle do escoamento superficial, bem como a minimização das consequências negativas provocadas pela intervenção antrópica e o uso da terra, pode-se adotar algumas medidas de sistema de drenagem, que tem como objetivo garantir a estabilização dos processos decorrentes da produção de sedimentos, bem como recuperar as áreas (estradas) já degradadas, sendo eficientes, econômicas e aplicadas conforme as necessidades locais (CUNHA, 2011). 


\section{Medidas de manutenção adotada nas estradas rurais da BRP}

Foram realizadas entrevistas semiestruturadas com os funcionários da Prefeitura Municipal de Guarapuava-PR responsáveis pela manutenção das estradas na bacia. Os operadores informaram que usam máquinas como Motoniveladora (patrol), Rolocompressor e Retroescavadeira, todos estes ligados diretamente a atividade de manutenção das estradas rurais da região.

Os mesmos destacaram que a adequação das estradas rurais envolve um conjunto de prática e manutenção com a finalidade de recuperação e conservação das estradas de terra, levando-se em consideração a sua ligação com as áreas agrícolas em Guarapuava. O objetivo é evitar a erosão do solo, a degradação do meio ambiente e a garantia de um tráfego normal de veículos, além de favorecer o escoamento da produção agrícola durante as épocas de chuvas e de secas.

Portanto, para que tal feito aconteça é realizada manutenção a cada 3 a 6 meses, podendo variar o tempo com o desgaste do local. Dentre os serviços prestados pela prefeitura também é realizada uma adequação nas estradas para evitar a erosão e degradação do ambiente, controlar as enxurrada do solo para os cursos d'água, limpeza de bueiros, compactação do cascalho, galerias e manilhamento.

Para o revestimento destas vias é utilizado materiais como o cascalho natural, pedra brita, evitando assim o atoleiro, bancos de areia, buracos, trepidação entre outros problemas. A utilização dos equipamentos é diversa sendo escolhidos em função do tipo do trabalho a realizar. A remoção de vegetação, nivelamento, compactação e drenagem, devem ser efetuadas por formar um caminho que torne fácil e seguro a deslocação do equipamento. Para isso são utilizados o trator de rastros, patrol, rolo compressor para compactação das pedras, retroescavadeira e pá-carregadeira, Figura 9.

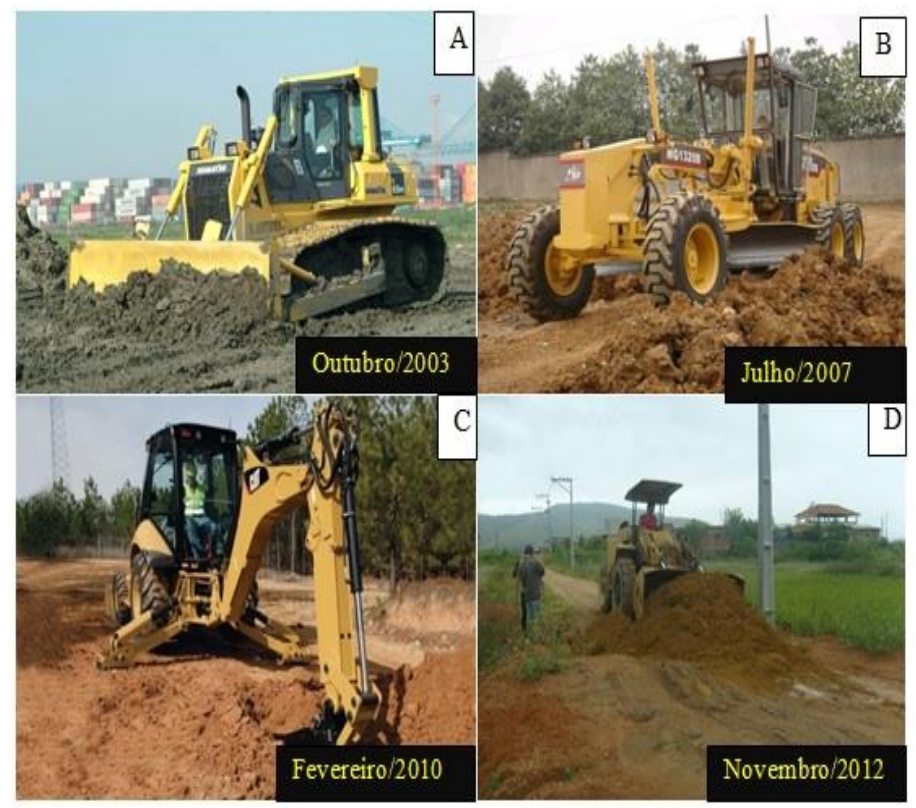

Figura 9 - Equipamentos utilizados na manutenção de estradas rurais. Em A, trator de rastros. Em B patrol (patrola). Em C retroescavadeira. Em D pá-carregadeira.

Fonte: (http://br.viarural.com/construcao/escavadeiras-pas/caterpillar/retroescavadeiras-420e-420e-it.htm) 
Relataram também que a manutenção destas vias visa conservar a superfície de rolamento razoavelmente isenta de irregularidades, firme e livre da perda excessiva de material solto, além de manter a declividade transversal do leito da estrada apropriada para assegurar o escoamento superficial das águas (DNER, 1981).

Grande parte da região Centro-Sul do Paraná (ex. BRP), particularmente, são terras dissecadas ocupadas por agricultura familiar, florestas e reflorestamento. Nas terras dissecadas, as estradas, carreadores e caminhos são implantados em diferentes unidades geomorfopedológicas, muitas vezes, não é considerada a aptidão do terreno. Por outro lado, a conservação das estradas rurais em terras dissecadas é realizada com dificuldade. Deste modo, muitos carreadores e caminhos internos das propriedades tornam-se intransitáveis devido ao forte ravinamento que se instalam sobre o leito dessas vias de circulação (THOMAZ, 2009).

Os maiores problemas na região são nos locais de subidas e os buracos que são constantes devidos às chuvas. No caso da BRP, grande parte das estradas foi construída em solos argilosos, o que facilita os problemas em épocas de chuva, como por exemplo, os atoleiros e a pista escorregadia (CUNHA, 2010).

Para corrigir o sistema de drenagem deficiente, é feito um abaulamento do leito da estrada e direcionando o escoamento da água para as leiras dimensionando corretamente as lombadas e melhorando o revestimento primário do leito da estrada.

Os pontos mais difíceis para a manutenção é a escassez de equipamentos e a dificuldade de locomoção da retirada do cascalho para revestimento. Portanto, a manutenção realizada nas estradas rurais segundo os operários é apropriada para a preservação e conservação, sendo que o patrolamento das vias é atividade principal executada na prefeitura.

\section{CONCLUSÕES}

A localização das estradas e a sua proximidade com os cursos d'água podem aumentar o transporte de sedimentos, quando não tratados adequadamente, ou diminuí-los, desde que sejam realizadas técnicas que contribuam com a minimização dos problemas gerados pelas mesmas, principalmente o assoreamento.

Verificou-se nos trechos avaliados que há dispositivos de drenagem, mas muitos desses estão sem manutenção ou estão inadequados, ou seja, foram construídos de forma irregular e por isso não têm a eficácia desejada, não contribuindo para a desaceleração do escoamento superficial.

As estradas rurais são fundamentais para ligação entre áreas rurais e urbanas, mas de todo modo para que estas cumpram com sua função é necessário que estejam em boas condições de uso. $\mathrm{Na}$ bacia em questão notou-se que em alguns casos existem manutenção de acordo com o 
recomendado na literatura, porém isso não ocorre de maneira uniforme e nem com o mesmo período de frequência em todas as unidades da bacia.

Sendo assim sugere-se que as próximas estradas implantadas na bacia, estejam localizadas adequadamente conforme recomendado na literatura. E que medidas de manutenção na faixa de rolamento sejam frequentes garantindo um bom estado de conservação. Por fim é fundamental que dissipadores de energia como caixas de contenção sejam implantados e mantidos de forma adequada que garanta a qualidade do solo e da água.

\section{AGRADECIMENTOS}

Ao CNPq: Apoio financeiro, Edital MCT/ CNPq 15/2007- Universal- Faixa B (processo 475161/2007-6) Projeto: Avaliação do aporte de sedimento proveniente de estradas rurais e de seus impactos na descarga sólida fluvial em suspensão, na bacia do Rio Guabiroba, Guarapuava-PR. À Coordenação de Aperfeiçoamento de Pessoal de Nível Superior (CAPES) por ter concedido bolsa e aos operários da prefeitura por ter concedido informações por meio da entrevista.

\section{REFERÊNCIAS}

BAESSO, D. P.; GONÇALVES, F. L. R. Estradas rurais: técnicas adequadas de manutenção. Florianópolis: DER, 2003. 204 p.

BUBLITZ, U.; CAMPOS, L.C. Adequação de estradas rurais em microbacias hidrogaficas: especificações e serviços. Curitiba: [s.n], 1992.70p.

CUNHA, M. C. Caracterização das estradas rurais não pavimentadas como elementos presentes na paisagem da Bacia Hidrográfica do Rio das Pedras, Guarapuava, Paraná. Rev. GEOMAE Campo Mourão, PR v.1n.2 p.73 - $912^{\circ}$ Sem 2010 ISSN 2178-3306

CUNHA, M. C. Avaliação da eficácia das caixas de contenção de sedimentos em estradas rurais não pavimentadas na Bacia do Rio das Pedras, Guarapuava, Paraná. Dissertação (mestrado). Universidade Estadual do Centro-Oeste. Guarapuava, Paraná, 132 p. 2011.

GONÇALVES, J. L. M. Conservação do solo. In. GONÇALVES, J. L. M.; STAPE, J. L. (Ed). Conservação e cultivo de solos para plantações florestais. Piracicaba: IPEF, 2002. cap. 2, p. 47129.

GUCINSKI, H.; FURNISS, M.J.; ZIEMER, R.R.; BROOKES, M.H. Forest roads: a synthesis of scientific information. USDA. Forest Service. PNW General Technical Report, Portland, n.509, p.1-103, 2001.

LANE P. N. J.; HAIRSINE P. B.; CROKE J. C.; TAKKEN I. 2006. Quantifying diffuse pathways for overland flow between roads and streams of the Mountain Ash forests of central Victoria, Australia. Hydrologic Processes 20: 1875-1884

LIMA, A. G. Controle geológico e hidráulico na morfologia do perfil longitudinal em rio sobre rochas vulcânicas básicas da formação serra geral no estado do Paraná. Tese (Doutorado). Universidade Federal de Santa Catarina. Florianópolis, 2009. 


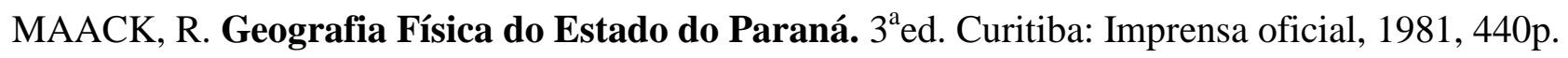

MACHADO C. C.; et. al. Durabilidade de solos estabilizados quimicamente com vistas á aplicação em estradas florestais. Revista Árvore, 2006; 30(6): 981-988. http://dx.doi.org/10. 1590/S010067622006000600013

ODA, S.; FERNANDES JÚNIOR, J. F.; SÓRIA, M. H. A. Implantação, localização e manutenção de estradas. Departamento de transporte-EESC-USP, Universidade de São Paulo, 2007.

THOMAZ, E. L.; VESTENA, L. R. Aspectos Climáticos de Guarapuava-PR. Guarapuava: Editora Unicentro, 2003.

THOMAZ, E. L. Processos Geomorfológicos e balanço de sedimentos em bacia de drenagem. In: Leandro Redin Vestena, Paulo Nobokuni, Márcia da Silva, Edivaldo Lopes Thomaz. Saberes Geográficos: Teorias e Aplicações. Guarapuava: Unicentro, 2009, 298p. 